\title{
HABILIDADES DE PENSAMENTO CRIATIVO EM CRIANÇAS INSTITUCIONALIZADAS E NÃO INSTITUCIONALIZADAS*
}

\author{
CREATIVE THINKING ABILITIES IN INSTITUTIONALIZED \\ AND NON INSTITUTIONALIZED CHILDREN
}

Paulo Gomes de SOUSA FILHO ${ }^{1}$

Eunice M. L. SORIANO ALENCAR ${ }^{2}$

\begin{abstract}
RESUMO
Este estudo examinou diferenças em habilidades de pensamento criativo entre 25 crianças institucionalizadas e 30 crianças não institucionalizadas, sendo 23 do sexo masculino e 32 do sexo feminino. Todas responderam a um teste de natureza verbal da Bateria Torrance de Pensamento Criativo (Torrance, 1974) e ao Teste de Pensamento Criativo - Produção Divergente (Urban \& Jellen, 1996). Não foram observadas diferenças significativas nas medidas de pensamento criativo entre crianças institucionalizadas e não institucionalizadas. Diferença significativa entre gêneros foi observada no Teste de Pensamento Criativo - Produção Divergente, a favor do gênero masculino, paralelamente a uma interação entre gênero e instituição neste teste. Observou-se também uma relação positiva entre os escores dos dois testes utilizados.
\end{abstract}

Palavras-chave: criatividade, criança institucionalizada, institucionalização, pensamento criativo.

\begin{abstract}
This study investigated the differences in creative thinking abilities among 25 institutionalized children and 30 non-institutionalized children, being 23 male and 30 female. These children answered a verbal test of the Torrance

(*) Este trabalho foi desenvolvido a partir da Dissertação de Mestrado do primeiro autor apresentada na Universidade Católica

(1) Professor do Curso de Graduação na Universidade Católica de Brasília. Endereço para correspondência: Rua: SQS 403
\end{abstract} de Brasília, sob orientação da co-autora. Bloco A - Brasília/DF - Cep: 70237-010 - E-mail: phoenix@zaz.com.br

(2) Professora do Curso de Mestrado da Universidade Católica de Brasília 
Tests of Creative Thinking (Torrance, 1974) and the Test of Creative Thinking - Divergent Production (Urban \& Jellen, 1996). No significant differences were observed among male and female children in the creative thinking abilities. However, a significant difference between gender was observed in the Test of Creative Thinking - Divergent Production, to the advantage of the male gender as far as an interaction between gender and institutionalization in the same test. It was observed also, a positive relation among the scores of the tests.

Key words: Creativity, institutionalized child, institutionalization, creative thinking.

\section{INTRODUÇÃO}

Em uma sociedade caracterizada pela urgência de novas soluções para velhos e novos problemas, pela tentativa de adaptação às constantes e, às vezes, surpreendentes mudanças e pela busca dos talentos, evidencia-se a importância e, conseqüentemente, a necessidade do estudo e investigação da criatividade. Fenômeno complexo e que assume múltiplas e variadas formas, a criatividade tem sido objeto de inúmeros estudos desde o discurso pronunciado por Guilford (1950) que, como presidente da Associação Americana de Psicologia, sugeriu a realização de pesquisas sobre dois aspectos fundamentais: (a) como identificar a criatividade em crianças; e (b) como promover o desenvolvimento da personalidade criativa.

Diversos pesquisadores têm dedicado esforços para investigar os distintos fatores que se relacionam com a expressão da criatividade. Alguns autores (Guilford, 1975; Sternberg, 1988; Torrance, 1987) enfatizam a relação do processo cognitivo com a criatividade. Outros (Lowen,1984; May,1982; Rogers, 1978) evidenciam a criatividade como fator básico na manutenção da saúde mental e da auto-realização. As características de um ambiente facilitador para a promoção do potencial criativo são também objeto de estudo de muitos pesquisadores (Amabile, 1996; Csikzentmihalyi, 1988, 1996). O que podemos observar na literatura é uma concordância entre os vários autores sobre a importância do potencial criativo e sua expressão, relacionando-o com aspectos cognitivos, auto-realização, saúde mental e com um ambiente propício ao seu desenvolvimento.

Apesar das muitas pesquisas realizadas nas últimas décadas, pode-se perceber que praticamente inexistem estudos relacionando criatividade aos efeitos da institucionalização precoce. Esta questão se torna-se relevante tendo em vista as proporções atingidas em nosso país, seja pelo número de menores abandonados, seja pelo grande número de instituições ou também pelas conseqüências para o contexto sociocultural.

Observa-se que, em muitos países, a prática de institucionalização de crianças caiu em desuso, a não ser em casos excepcionais: crianças cujos problemas não Ihes permitem permanecer em suas comunidades. O oposto acontece no Brasil, onde o índice de crianças institucionalizadas tem crescido sempre. De acordo com Rizzini (1989), existem milhares de instituições espalhadas pelo país, de todos os tamanhos e credos, mantendo práticas desumanas e ultrapassadas. Essa autora enfatiza que, em comum, essas instituições têm uma função que não deveria existir em pleno início de um novo milênio: a de dispensário, asilo e depósito de crianças.

A pesquisa que focaliza a influência dos diferentes contextos sobre o processo de desenvolvimento infantil vem ganhando crescente destaque e importância. Durante muitos anos, 0 papel da interação de fatores internos e externos 
no desenvolvimento não foi adequadamente destacado.

Além das concepções "natistas" e das concepções ambientalistas, uma terceira linha de estudos sugere que existe uma complexa interação de forças internas e forças do ambiente que resultariam no desenvolvimento. Segundo Wallon (1995), entre o indivíduo e o seu meio há uma unidade indissolúvel. Não há oposição entre o desenvolvimento psicobiológico e as condições sociais que o impulsionam. Wallon acredita que a sociedade é, para o homem, uma necessidade orgânica que determina o seu desenvolvimento. Ressalta ainda que a aquisição do conhecimento é um patrimônio extrabiológico do grupo no qual o indivíduo vai evoluir.

Piaget (1993) afirmou que as influências do meio e da hereditariedade são recíprocas, não sendo nenhuma das duas absolutas. Esta é uma noção válida para todo o desenvolvimento humano, inclusive para o desenvolvimento da criatividade.

Dentre os pesquisadores que chamam a atenção para a inter-relação entre a pessoa, o produto criativo e o sistema social, destacam-se Amabile (1996) e Csikszentmihalyi (1996), que desenvolveram abordagens sistêmicas na busca desta integração. Amabile (1996) aponta como componentes do comportamento criativo três aspectos: (a) habilidades relevantes no domínio de um conhecimento (área de conhecimento específico); (b) habilidades relevantes para a criatividade incluindo a cognição e personalidade do indivíduo; e (c) motivação para a tarefa, abrangendo motivação intrínseca e extrínseca.

Csikszentmihalyi (1996) afirma que não podemos estudar a criatividade isolando o indivíduo e sua produção do meio social e histórico em que suas ações ocorreram. Este autor considera que a criatividade nunca é o resultado de uma ação somente individual e sim o produto de três forças principais: (a) um grupo de instituições sociais, ou campo, que seleciona as produções que quer preservar; (b) um domínio de cultura que deve preservar e transmitir as idéias selecionadas para as gerações seguintes; e (c) o indivíduo que traz alguma mudança no domínio, que o campo deve considerar criativa.

Essa concepção de criatividade como um processo individual e um produto social que não pode ser desvinculado do momento social-histórico é também postulada pelos teóricos da psicologia soviética (Ponomarev em Silva, 1993;Vygotsky, 1990; Yaroshevskii, 1987). Para esses teóricos, o homem é visto como resultado da interação entre três amplos aspectos: (a) o fisiológico; (b) o histórico-social; e (c) o individual. Nesta perspectiva, a determinação históricosocial está na gênese da ação humana (Silva, 1993).

Nenhuma invenção ou descoberta científica ocorre antes que os materiais e as condições psicológicas necessárias para sua origem estejam presentes. Para Vygotsky, não existe uma criatividade individual; existe sempre um coeficiente social (em Smolucha, 1992). Da mesma forma, Ponomarev (em Silva, 1993) afirma que "o mecanismo de cognição individual é formado sob a influência direta do desenvolvimento da atividade cognitiva da sociedade, ou seja, o determinismo sócio-histórico poderia também ser estendido à noção do mecanismo psicológico da criatividade" (p. 151).

A determinação histórico-cultural da criatividade se manifesta de forma mais acentuada com Yaroshevskii (1987). Para esse autor, a cultura é construída em fundações sociais e históricas e a tentativa de reduzi-la a aspectos de associações de idéias, atos de intuição, complexos emocionais, psicodinâmicas inconscientes impede o entendimento da estrutura e dos mecanismos intrínsecos do seu desenvolvimento. Yaroshevskii afirma, de forma enfática, que se os princípios do historicismo e determinismo sociocultural, bem como uma abordagem sistêmica não forem introduzidas na área da criatividade, a mesma sofrerá uma estagnação.

A influência do ambiente familiar para a promoção da criatividade tem sido destacada 
por muitos pesquisadores (Alencar, 1993; Amabile, 1996; Dacey, 1989).

Para Alencar (1993), a criatividade necessita de condições adequadas para desenvolver-se. Para esta autora, algumas destas condições relacionam-se com o Zeitgeist, o espírito da época, com o clima psicológico e/ou social que predomina em uma determinada sociedade. Alencar chama a atenção para o fato de que "estas condições, mais ou menos favoráveis, estariam também relacionadas aos valores dominantes na família, aos traços de personalidade e características aí reforçados e cultivados" (p. 57).

Amabile (1996) enfatiza que as famílias que melhor promovem a criatividade em seus filhos caracterizam-se por um baixo nível de autoritarismo e restrições, valorizam a independência e mantêm um contato emocional moderado. Ao fazer uma revisão sobre estudos que correlacionam ordem de nascimento ou ausência do pai com a criatividade, Amabile (1996) afirma que as características dos pais estão mais fortemente relacionadas à criatividade dos filhos do que a constelação familiar. Amabile afirma que existe uma grande evidência de que as crianças tendem a ser mais criativas quando seus pais têm personalidade assertiva e são relativamente pouco preocupados em seguir padrões de comportamento social.

Alencar (1993) salienta alguns fatores presentes no ambiente familiar que podem facilitar o desenvolvimento da criatividade, como as características de personalidade dos pais, suas atitudes com relação à forma adequada de se criar filhos, suas expectativas com relação à criança, seu grau de confiança na capacidade da criança de explorar o mundo e de ser responsável; o grau de aceitação e respeito pelas idéias, sentimentos, indagações e fantasias da criança.

Também Dacey (1989), em um estudo no qual foram investigadas as famílias de 56 adolescentes altamente criativos comparadas a uma amostra de 20 outras famílias que foram selecionadas porque nenhum dos seus componentes foi identificado como sendo criativo, constatou que: (a) embora os pais com crianças criativas tivessem a tendência de mencionar poucas regras, eles apresentavam um sistema de valore claro e coerente; (b) o senso de humor é importante nas famílias criativas; (c) nessas famílias, imaginação e honestidade eram mais valorizadas que boas notas e boa saúde; (d) nas famílias criativas, praticamente todos os pais tinham interesses fora do trabalho; e (e) crianças do grupo criativo sofreram mais traumas (mágoa, raiva ou ambos) que as crianças do grupo comparativo.

Torna-se importante chamar a atenção para o que enfatiza Alencar (1993) “....a maneira como o indivíduo se percebe (como capaz de criar ou, pelo contrário, como incompetente ou incapaz), as suas crenças e sentimentos a respeito de si mesmo e de suas capacidades, é formada durante os primeiros anos de sua vida, sofrendo uma profunda influência de seus primeiros agentes socializadores, os pais..." (p. 69). Nesse sentido, voltamos nossa atenção para as crianças que viveram desde a mais tenra infância em instituições e os efeitos desse ambiente no seu desenvolvimento.

Lapassade (1977) salienta que a palavra instituição significa etimologicamente "um sistema de normas que estruturam um grupo social, regulam sua vida e seu funcionamento" (p. 287). Esta palavra pode também, quando considerada como um ato, tomar o sentido de "instituir", proveniente do latin instituere, que quer dizer "estabelecer, construir, preparar, instruir, dispor, educar, formar" (p. 287). Segundo Goffman (1987), uma "instituição total é um local de residência e trabalho onde um grande número de indivíduos com situação semelhante, separados da sociedade mais ampla por considerável período de tempo, levam uma vida fechada e formalmente administrada" (p.11).

Eizirik (1988) enfatiza alguns aspectos que caracterizam as instituições sociais, salientando dentre eles: um sistema de normas interno e externo; um sistema de avaliação; e um sistema de trocas que funciona como estruturas 
reguladoras e organizadoras desses sistemas. Segundo a mesma autora, as instituições podem ainda ser vistas como "sistemas simbólicos que definem e regulam padrões de funcionamento, rituais, direitos e deveres que são estritamente vinculados à natureza e à característica de cada instituição" (p. 31). Os ambientes institucionais têm sido descritos, freqüentemente, como influência negativa para o processo evolutivo da criança. Historicamente, esses ambientes têm sido organizados a partir de um conjunto de elementos que contribuem de forma significativa para esse processo. Em geral, o meio institucional é relativamente desestimulante para a criança em desenvolvimento, apresentando problemas como superlotação, pouco pessoal qualificado, espaço reduzido e com poucas chances de oferecer o tipo de estimulação sensorial adequada à criança.

Yarrow (em Weber \& Kossobudszki, 1996) constatou que o singular meio físico das instituições se caracterizava por ser monótono, com pouca estimulação visual, auditiva, motora e lingüística. O meio emocional demonstrava ausência de variações quer positivas quer negativas, e o meio social era bastante restrito em vários aspectos. Estas autoras salientam que, nas instituições: (a) a oportunidade de praticar certas habilidades comuns na vida do lar é praticamente impossível, por estar a criança mais nova confinada ao berço, limitada na locomoção e exploração ambiental, além de não ser observada individualmente para reforço de comportamentos novos desejáveis; (b) a motivação provinda de pais, irmãos e outros familiares encontra-se quase totalmente eliminada; (c) a rotina da instituição, que faz com que a equipe de funcionários atenda ao maior número de crianças em menor espaço de tempo, faz com que as necessidades da criança passem despercebidas.

Weber e Kossobudszki (1996) constataram que existem distintos tipos de instituições para crianças e adolescentes e que, apesar das diferenças, existe sempre falta de contato físico, ausência de reforçadores e verbalização limitada.
Segundo essas autoras, "os dirigentes dessas instituições, tanto governamentais quanto particulares, na maioria das vezes, têm idéias preconcebidas e errôneas sobre o desenvolvimento infantil" (p. 93). Essas autoras salientam, após diversas observações em orfanatos, que existe uma intensa massificação de atitudes em todos os momentos numa instituição, desde o modo como uma cama deve ser arrumada até a proibição para freqüentar seu próprio quarto durante o dia ou deitar-se para relaxar. Consideram que "esse tipo de massificação suprime o senso crítico, a criatividade e a capacidade de iniciativa das crianças, pois elas acabam sempre fazendo o que os outros, enquanto instituição, mandam e não o que elas desejam em determinado momento" (p. 44).

Para Berger e Luckmann (1976), "as instituições, também, pelo simples fato de existirem, controlam a conduta humana estabelecendo padrões previamente definidos de conduta, que canalizam em uma direção por oposição às muitas outras direções que seriam teoricamente possíveis" (p. 80).

Essas normas de conduta opõem-se diametralmente ao que Stein (1974) destaca ao examinar as características de um ambiente facilitador e estimulador da criatividade. Segundo Stein, "se aqueles que circundam o indivíduo não valorizam a criatividade, não oferecem o ambiente e o apoio necessário, não aceitam o trabalho criativo quando este é apresentado, então é possível que os esforços criativos do indivíduo encontrem obstáculos sérios, senão intransponíveis" (p. 12). Ressalta também que, para que a sociedade favoreça a criatividade é necessário que ela: (a) ofereça ao indivíduo um número razoável de experiências em diversas áreas; (b) abra espaço e encoraje experiências internas e externas de seus membros; (c) valorize a mudança e a originalidade; (d) dê status e reconhecimento social aos indivíduos criativos; (e) ofereça a todos os seus cidadãos possibilidades de estudo e oportunidade de expressão e questionamento. 
As características do ambiente institucional anteriormente citadas contrastam com uma lista das condições psicológicas e sociais, organizada por Torrance (1987) após examinar a questão das condições adequadas ao funcionamento dos processos mentais que estimulam a criatividade. Para Torrance, deveria existir: (a) ausência de ameaça grave ao selfe disposição para correr riscos; (b) autopercepção, contato com seus próprios sentimentos; (c) auto-afirmação, ver a si mesmo como diferente dos outros; (d) abertura para idéias dos outros e confiança nas suas percepções e idéias; e (e) relações interpessoais equilibradas. Ainda enfatizando as condições ambientais adequadas que promovem o comportamento criativo, Taylor (em Alencar, 1993) destaca, entre outros, os seguintes pontos: (a) redução de fatores que produzem frustração; (b) redução de experiências e situações competitivas que impliquem ganhos ou perdas; (c) encorajamento do pensamento divergente; (d) eliminação de ameaças ambientais; (e) aceitação da fantasia; (f) minimização de coerções; (g) ajuda à pessoa em sua compreensão de si e de sua divergência em relação às normas.

Muitos estudos foram conduzidos com o objetivo de investigar a inteligência, linguagem e socialização em crianças institucionalizadas (Bohman \& Sigvardsson, 1979; Manesh, Mojdehi \& Tashakkori, 1984; Tizard \& Hodgers, 1978). Observa-se, entretanto, uma carência de pesquisas relativas à extensão da influência do ambiente institucional no desenvolvimento de habilidades criativas de crianças. Este foi um dos fatores que nos levaram ao desenvolvimento do presente estudo, que teve como objetivo responder às seguintes questões:

1) Existem diferenças entre crianças institucionalizadas e não institucionalizadas em habilidades de pensamento criativo avaliadas por meio de testes padronizados?

2) Existem diferenças entre crianças do gênero masculino e do gênero feminino em habilidades do pensamento criativo avaliadas por meio de testes padronizados?

3) Existe interação entre institucionalização e gênero nas habilidades de pensamento criativo?

4) Existe uma relação positiva entre os resultados obtidos no Teste Torrance do Pensamento Criativo (Torrance, 1974) e no Teste do Pensamento Criativo - Produção Divergente (Urban \& Jellen, 1996)?

\section{METODOLOGIA}

\section{Participantes}

Conforme o item III, Aspectos Éticos da Pesquisa envolvendo Seres Humanos, §1, sobre o consentimento livre e esclarecido dos indivíduos-alvo, os participantes foram esclarecidos sobre os objetivos e procedimentos da pesquisa. Participaram do estudo 55 crianças de 7 a 12 anos de idade, sendo 23 do gênero masculino e 32 do gênero feminino, de nível socioeconômico baixo. Vinte e cinco eram crianças institucionalizadas e 30 eram crianças criadas em residências com pai e mãe presentes. A maioria das crianças institucionalizadas eram provenientes de famílias cujos pais estavam ausentes por abandono ou cumprimento de penas em prisão. Estas crianças foram encaminhadas à instituição pelo Centro de Recepçãoe Triagem-CRT, órgão da Fundação do Serviço Social e pelos Conselho Tutelar e Vara da Infância e Juventude ligados ao Ministério da Justiça, localizados no Distrito Federal.

\section{Instrumentos}

Dois instrumentos para a avaliação das habilidades do pensamento criativo foram utilizados neste estudo: Um teste de natureza verbal da Bateria Torrance de Pensamento Criativo (Torrance, 1974) e o Teste de Pensamento Criativo - Produção Divergente (Urban \& Jellen, 1996), de natureza figurativa. 
A Bateria Torrance de Pensamento Criativo (Torrance, 1974) é composta de vários testes, sendo alguns de natureza verbal e outros de natureza figurativa. $O$ teste de natureza verbal (Usos Incomuns-Caixas de Papelão) foi utilizado neste estudo. As respostas ao mesmo foram avaliadas considerando-se as seguintes categorias: a) fluência, que é o número total de respostas relevantes, sendo a relevância definida em termos dos requisitos da tarefa como apresentada nas instruções; b) flexibilidade, que é o número de diferentes categorias em que as respostas apresentadas podem ser classificadas; e c) originalidade, que diz respeito à novidade estatística das respostas apresentadas, sendo que essa novidade estatística está relacionada à freqüência de ocorrência das respostas na população. Aquelas que ocorrem em apenas $2 \%$ das respostas apresentadas recebem escore mais alto (ex. 2), enquanto que as que ocorrem com mais de $5 \%$ de freqüência recebem o escore mais baixo (ex. 1). Um estudo exploratório é realizado para a obtenção das respostas mais comuns e mais raras.

As habilidades do pensamento criativo foram aferidas também, pela forma A do Teste de Pensamento Criativo - Produção Divergente (TCP - DP) (Urban \& Jellen, 1996), produzido e validado na Alemanha. O número máximo de pontos do Teste de Pensamento Criativo - Produção divergente é 72 , os quais podem ser transformados em uma classe especial de percentil ou T-escore.

\section{RESULTADOS}

Existem diferenças entre crianças institucionalizadas e não institucionalizadas nas habilidades de pensamento criativo avaliadas por meio de testes padronizados?

Para responder a essa questão, uma análise de variância multivariada (MANOVA) foi realizada tendo institucionalização e gênero como variáveis independentes e fluência, flexibilidade e originalidade no Teste Torrance como variáveis dependentes. Como critério de teste de significância foi empregado o Wilk's lambda, conforme sugerem Tabachnick e Fidell (1996). A MANOVA não revelou diferenças significativas entre as crianças institucionalizadas e não institucionalizadas nas medidas de fluência, flexibilidade e originalidade $F[1,50]=1,56 ; p=0,21$.

Apesar da MANOVA não ter indicado diferenças significativas entre os dois grupos com relação às variáveis medidas pelo Teste Torrance de Pensamento Criativo, observou-se que as crianças não institucionalizadas obtiveram valores ligeiramente superiores em fluência $(M=17,93 ; D P=11,11)$, flexibilidade $(M=7,03$; $\mathrm{DP}=3,93)$ e originalidade $(\mathrm{M}=9,37 ; \mathrm{DP}=8,54)$ comparativamente às crianças institucionalizadas que obtiveram respectivamente $M=12,88$; $\mathrm{DP}=8,89$ para fluência, $M=6,08 ; \mathrm{DP}=3,41$ para flexibilidade e $\mathrm{M}=7,64$ e $\mathrm{DP}=6,52$ para originalidade.

Com relação ao escore total no Teste Torrance de Pensamento Criativo (Torrance, 1974), obtido por meio da soma dos escores de fluência, flexibilidade e originalidade, observou-se uma superioridade das crianças não institucionalizadas ( $M=34,33$; $D P=21,91)$ em relação às institucionalizadas $(M=27$; $\mathrm{DP}=18,43)$.

Uma análise de variância 2x2 foi realizada, tendo como variáveis independentes institucionalização e gênero e como variável dependente o escore total no Teste de Pensamento Criativo -Produção Divergente (Urban \& Jellen, 1996). A diferença observada entre crianças institucionalizadas e não-institucionalizadas no escore total do teste Pensamento Criativo-Produção Divergente não foi significativa $F[1,51]=1,25$; $p=0,26$.

Existem diferenças entre crianças do gênero masculino e do gênero feminino nas habilidades do pensamento criativo avaliadas por meio de testes padronizados?

A análise de variância multivariada (MANOVA), tendo o Wilk's lambda como critério de significância e apresentando institucionaliza- 
ção e gênero como variáveis independentes e os escores de fluência, flexibilidade e originalidade como variáveis dependentes, não evidenciou diferenças significativas entre as amostras do gênero masculino e do feminino $F[3,47]=1,12$; $p=0,34$.

Apesar dessa análise não ter indicado diferenças significativas entre as crianças do gênero masculino e do gênero feminino nos escores de fluência, flexibilidade e originalidade no Teste Torrance de Pensamento Criativo, observou-se que as crianças da amostra masculina obtiveram valores maiores quando comparadas com a amostra feminina, em fluência $\left(M_{\text {masc. }}=16,92 ; D P=12,26 ; M_{\text {fem. }}=14,57\right.$; $\mathrm{DP}=8,59)$, flexibilidade $\left(\mathrm{M}_{\text {masc }}=7,32\right.$; $D P=4,36 ; M_{\text {fem }}=6,00 ; D P=3,01$ ) e originalidade $\left(M_{\text {masc. }}=10,4 ; D P=8,38 ; M_{\text {fem. }}=7,07 ; D P=6,79\right)$.

Os resultados no escore total do Teste Torrance de Pensamento Criativo também revelaram valores superiores para as crianças do gênero masculino $(M=34,64 ; D P=24,03)$ quando comparados aos valores obtidos pelas do gênero feminino ( $M=27,97$; $D P=16,96)$.

Foi realizada uma análise de variância (ANOVA), tendo gênero como variável independente e o resultado no Teste de Pensamento Criativo - Produção Divergente (Urban \& Jellen, 1996) como variável dependente. A ANOVA mostrou que as diferenças encontradas entre as crianças do gênero masculino e do feminino foram significativas $F[1,51]=10,4 ; p=0,01$, a favor da amostra masculina $(M=22,28$; $\mathrm{DP}=8,6)$ comparativamente à amostra feminina $(M=16,23 ; D P=6,37)($ ver tabela 1$)$.
Existe interação entre institucionalização e gênero com relação às habilidades de pensamento criativo?

Foi realizada uma análise multivariada de variância (MANOVA) utilizando o Wilk's lambda como critério de significância, e apresentando gênero e institucionalização como fatores fixos e fluência, flexibilidade e originalidade como fatores dependentes. A MANOVA não revelou resultados significativos $(F[3,47]=1,37 p=0,26)$.

Por outro lado, foi realizada a análise de variância (ANOVA), tendo instituição e gênero como variáveis independentes e o escore total no Teste de Pensamento Criativo - Produção Divergente (Urban \& Jellen, 1996) como variável dependente, revelando uma interação significativa entre gênero e institucionalização ( $F[1$, $51]=5,46 ; p=0,02)$.

A inspeção das médias revelou que as crianças do sexo masculino institucionalizadas apresentaram um desempenho significativamente superior no Teste de Pensamento Criativo - Produção Divergente de Urban \& Jellen (1996) $(M=23,7 ; D P=11,54)$ quando comparadas às crianças do sexo feminino institucionalizadas $(M=12,87$; $D P=4,6)$. Por outro lado, as crianças do gênero masculino não institucionalizadas apresentaram um desempenho superior no Teste de Pensamento Criativo-Produção Divergente $(M=21,33 ; D P=6,22)$ quando comparadas às crianças do gênero feminino não institucionalizadas $(M=19,6$; $\mathrm{DP}=6,21)$.

Tabela 1. Média e Desvio Padrão para o Escore Total do Teste de Pensamento Criativo - Produção Divergente de Crianças Institucionalizadas e Não Institucionalizadas do Sexo Masculino e Feminino

\begin{tabular}{lccccccccc}
\hline & \multicolumn{3}{c}{ Instit. } & \multicolumn{3}{c}{ Não Instit. } & \multicolumn{3}{c}{ Total } \\
\cline { 2 - 10 } Gênero & $\mathrm{X}$ & $\mathrm{DP}$ & $\mathrm{N}$ & $\mathrm{X}$ & $\mathrm{DP}$ & $\mathrm{N}$ & $\mathrm{X}$ & $\mathrm{DP}$ & $\mathrm{N}$ \\
\hline Masculino & 23,7 & 11,54 & 10 & 21,33 & 6,22 & 15 & 22,28 & 8,6 & 25 \\
Feminino & 12,87 & 4,6 & 15 & 19,6 & 6,21 & 15 & 16,23 & 6,37 & 30 \\
\hline
\end{tabular}


Há uma relação significativa entre os resultados no Teste Torrance de Pensamento Criativo (Usos Incomuns) e no Teste de Pensamento Criativo - Produção Divergente?

Para investigar a validade convergente das medidas de criatividade foi correlacionado o escore total do Teste de Pensamento Criativo (Urban \& Jellen, 1996) com a soma dos escores de fluência, flexibilidade e originalidade do Teste Torrance de Pensamento Criativo (Torrance, 1974). Os resultados indicaram correlação positiva moderada entre os dois escores $(r=0,31$; $p=0,21)$.

\section{DISCUSSÃO}

Quanto à primeira questão, uma possível explicação para os resultados obtidos no estudo diz respeito às condições da instituição, pois esta se caracteriza por um padrão adequado de atendimento das crianças que para lá se dirigem, padrão esse muito distante da média das instituições voltadas para o mesmo tipo de atendimento.

Como Rutter (1980) enfatiza, os efeitos residuais das experiências precoces no comportamento posterior do indivíduo tendema ser suavizados por causa de mudanças maturacionais que acontecem principalmente na primeira infância e também por causa dos efeitos benéficos de experiências positivas vividas posteriormente. No caso da instituição onde os dados foram coletados em particular, as crianças são admitidas antes de um ano de idade, provenientes de ambientes extremamente adversos. O novo ambiente proporcionado pela instituição caracteriza-se por amplos espaços, boa alimentação, melhor qualidade das relações sociais, presença de uma mãe social, atendimento médico/odontológico/psicológico, entre outros, parecendo agir no sentido de diminuir e/ou suprimir os possíveis efeitos do ambiente em que viviam anteriormente.

Resultados desta natureza têm sido apontados por alguns autores que insistem na intervenção e no resultado desta intervenção a longo prazo. Darlington, Royce, Snipper, Murray e Lazar (em Wachs \& Gruen, 1982) constataram que os efeitos da intervenção precoce nos níveis de QI de crianças de orfanato podem decair em quatro anos se essa intervenção cessar. Foi observado no presente estudo, que a instituição se caracteriza por uma ótima infra-estrutura em termos de estimulação cognitiva, contando com a ajuda de voluntários que se dedicam ao ensino extracurricular das crianças. Em contraste, as crianças não institucionalizadas caracterizam-se por viver em lares próprios, com a presença de pai e mãe do nível socioeconômico baixo. Em geral, não contam com uma estrutura de acompanhamento escolar assim como não contam com um atendimento médico/odontológico/psicológico.

A qualidade das experiências posteriores a algum tipo de ambiente adverso no início da vida foi também enfatizada por Wachs e Gruen (1982). Esses autores evidenciaram a importância das experiências vividas posteriormente à privação e seu papel na diminuição dos efeitos negativos do ambiente inicial. De forma mais contundente, Clarke e Clarke (1986) afirmam que as experiências posteriores teriam um papel equivalente às experiências precoces no desenvolvimento do indivíduo.

Parece, então, que a qualidade dos serviços da instituição tem agido no sentido de diminuir os possíveis efeitos negativos do ambiente inicial da criança. Como enfatizam Wachs e Gruen (1982), “....a presença de uma variedade de pessoas acessíveis ou brinquedos é positivamente relacionada a um desenvolvimento cognitivo/intelectual precoce podendo ter conseqüências de longa duração" (p. 48).

Por outro lado, embora as diferenças entre os escores do teste do pensamento criativo entre a amostra institucionalizada e não institucionalizada não tenham sido significativas, é importante ressaltar que, na maioria das medidas analisadas, a amostra não institucionalizada obteve médias ligeiramente superiores quando comparada à amostra institucionalizada, 
indicando que, mesmo em uma instituição de boa qualidade, alguns dos efeitos adversos iniciais podem persistir, por mínimos que sejam, estando, portanto, na raiz dessa diferença. É importante frisar que, embora as atendentes da instituição se caracterizem pela dedicação e carinho para com as crianças, alguns estudos têm mostrado que o ambiente de cuidado provido pelos pais é significativamente correlacionado com medidas de competência cognitiva das crianças (ClarkeStewart, 1973), indicando a importância da relação familiar para o desenvolvimento cognitivo da criança.

Quanto à segunda questão, os resultados deste estudo indicaram que as diferenças encontradas entre as amostras do gênero masculino e do feminino foram significativas apenas no Teste de Pensamento Criativo - Produção Divergente (Urban \& Jellen, 1996).

No entanto, o uso de estatística multivariada combinado com amostras pequenas pode traduzir-se em dificuldades de interpretação e generalização dos resultados. Wachs e Gruen (1982) apontam problemas que podem surgir do uso da estatística multivariada quando utilizada com amostras pequenas, sugerindo precaução na interpretação dos resultados. Tendo em vista esse fato, a análise dos resultados obtidos pelos participantes do estudo no Teste Torrance do Pensamento Criativo pode ter sofrido alguma interferência devido ao tamanho da amostra.

O uso de apenas um dos testes (Usos Incomuns) da Bateria Torrance de Pensamento Criativo também pode ter contribuído para o resultado final da análise de variância multivariada. Esse teste (Usos Incomuns) pode ter sido objeto de alguma dificuldade para sua realização por parte das crianças de 7 e 8 anos de idade devido à sua natureza escrita. Observou-se que algumas crianças dessa faixa etária apresentaram uma certa dificuldade tanto na escrita como na concentração na tarefa.

Apesar desse fato, convém ressaltar que uma análise das médias das amostras do gênero masculino e do feminino, tanto institucionalizada como não institucionalizada, indicou uma pequena superioridade das crianças do gênero masculino com relação às médias das crianças do gênero feminino e também das crianças do gênero feminino da amostra não institucionalizada com relação às crianças do gênero feminino institucionalizadas nos escores de fluência, flexibilidade e originalidade do Teste Torrance, 0 que sugere que o ambiente institucional parece ter um maior efeito negativo no desenvolvimento das habilidades do pensamento criativo em meninas do que em meninos.

Complementando os resultados descritos anteriormente no que diz respeito ao Teste Torrance de Pensamento Criativo, os resultados obtidos no Teste de Pensamento Criativo - Produção Divergente (Urban \& Jellen, 1996) indicaram uma diferença significativa entre os participantes do gênero masculino e os do gênero feminino a favor dos primeiros. Uma possível explicação pode ser encontrada no tipo de estimulação que pode estar sendo promovida e nos padrões comportamentais implementados no interior da instituição. Os efeitos negativos de ambientes pobres em estímulos como orfanatos têm sido bem documentados por autores como Hunt(1975). Este autor aponta a relação de ambientes caracterizados pela baixa estimulação com a motivação intrínseca, entendendo-a como uma das maiores necessidades desenvolvimentais para crianças, sendo relacionada ao processamento de estímulos ou informações. Ambientes que não provêm as necessidades de estímulos adequados para a criança processar, ou que restringem o acesso a informações limitando a exploração, podem agir como um impedimento ao desenvolvimento cognitivo e, conseqüentemente, ao pensamento criativo. Levando-se em consideração, então, a importância da motivação intrínseca, também enfatizada por Amabile (1996), poderíamos questionar se estão sendo oferecidas situações de acesso a estímulos ambientais de forma igualitária tanto às crianças do gênero masculino como àquelas do gênero feminino. É de conhecimento que existe uma clara diferenciação entre gêneros. Tradicionalmente, 
as meninas costumam ser reforçadas ao demonstrar determinados comportamentos como passividade, demonstração de fraqueza, sensibilidade, enquanto aos meninos são propiciadas situações para que demonstrem características como agressividade, independência, força. Devido a fatores sócio-históricos, os modelos e padrões educativos em meninos e meninas são diferentes e tratam de perpetuar os papéis socialmente designados a ambos os sexos. Neste sentido, Martinez (1999) ressalta que

"A maior estimulação que, por regra geral, é recebida pelos meninos, unida à valorização de suas realizações intelectuais e a competitividade entre outros aspectos, em contraposição a uma educação mais passiva das meninas e a transmissão a elas dos valores tradicionais do 'feminino', condiciona um desenvolvimento diferenciado de capacidades, motivos, aspirações e valores que favorece a criatividade masculina e limita a feminina" (p. 2).

É possível que condicionamentos culturais estejam sendo repetidos de forma mais acentuada no interior da instituição. Horner (1972) enfatiza que a dependência é reforçada para as meninas e punida para os meninos. Em geral, espera-se de meninas comportamentos como cooperar, dividir, ajudar.

Essa constatação de Horner coincide com os estudos relacionados aos estereótipos de gênero. Deaux e Lewis (em Golombok \& Fivush, 1994) sustentam que o simples fato de saber que um indivíduo é do gênero feminino implica que a pessoa terá certas características físicas (voz macia, suavidade de movimentos) e certos traços psicológicos (dependência, mais emocional) e participará em tipos particulares de atividades (cuidar de crianças, cozinhar).

Com relação àterceira questão, nos resultados do Teste de Pensamento Criativo - Produção Divergente (Urban \& Jellen, 1996), observou-se uma interação entre gênero e institucionalização. Apenas as crianças do gênero masculino institucionalizadas apresentaram um desempenho significativamente superior quando comparadas às crianças do gênero feminino institucionalizadas.

Esses resultados parecem indicar que existem fatores presentes no interior da instituição que agem no sentido de solapar o desenvolvimento das habilidades do pensamento criativo em meninas.

Com relação à quarta questão, os resultados obtidos sugerem uma relação positiva moderada entre o Teste Torrance de Pensamento Criativo e o Teste de Pensamento Criativo - Produção Divergente (Urban \& Jellen, 1996). Isto constitui uma contribuição à validade concorrente do referido teste.

Os resultados obtidos no estudo alertam para o fato de que o potencial criador de gerações de crianças pode estar sendo comprometido de forma decisiva, sendo que as meninas parecem sofrer de forma mais significativa essa perda. Seria de grande relevância o desenvolvimento de estratégias que viessem sanar ou mesmo minimizar essa perda. Afiguram-se como prementes novas pesquisas no campo, que levantem as variáveis responsáveis por este quadro, a fim de que condições mais favoráveis ao desenvolvimento do potencial criador sejam propiciadas.

\section{REFERÊNCIAS BIBLIOGRÁFICAS}

ALENCAR, E. M. L. S. (1993). Criatividade. Brasília: Editora Universidade de Brasília.

AMABILE, T. M. (1996). Creativity in context. Boulder, CO: Westview Press.

BERGER, P. L., \& Luckmann, T. (1976). A construção da realidade. Petrópolis: Vozes.

BOHMAN, M., \& Sigvardsson, S. (1979). Long-term effects of early institutional care: A prospective longitudinal study. Journal of Child Psychology and Psychiatry, 20, 111-117.

CLARKE, A. M., \& Clarke, A. D. B. (1986). Thirty years of child psychology: A selective review. Journal of Child Psychology and Psychiatry, 27, 719-759. 
CLARKE-STERWART, K. A. (1973). Interaction between mother and their young children: Characteristics and consequences. Monographs of the Society for Research in Child Development, 38, 6-7.

CSIKSZENTMIHALYI, M. (1988). The domain of creativity. Trabalho apresentado no congresso de criatividade. Pitzer College, Claremont, EUA.

CSIKSZENTMIHALYI, M. (1996). Creativity. New York: Harper Collins.

DACEY, J. S. (1989). Discriminating characteristics of the families of highly creative adolescents. Journal of Creative Behavior, 23, 263-271.

EIZIRIK, M. F. (1988). Instituição, educação e trabalho: elementos para uma dialética de transformação. Psicologia, Ciência e Profissão, 28-32.

GOFFMAN, E. (1987). Manicômios, prisões e conventos. São Paulo: Perspectiva.

GOLOMBOK, S., \& Fivush, R. (1994). Gender development. Cambridge: Cambridge Press.

GUILFORD, J. P. (1950). Creativity. American Psychologist, 5, 444-454.

GUILFORD, J. P. (1975). Varieties of creative giftedness, their measurement and development. The Gifted Quarterly, 19, 285-297.

HORNER, M. S. (1972). Toward an understanding of achievement related conflicts in women. Journal of Social Issues, 28, 1071-1081.

HUNT, J. McV. (1975). Reflections on a decade of early education. Journal of Abnormal Child Psychology, 3, 275-330.

LAPASSADE, G. (1977). Grupos, organizações e instituições. Rio de Janeiro: Franscisco Alves.

LOWEN, A. (1984). Prazer: uma abordagem criativa da vida. São Paulo: Summus.

MANESH, Y. H., Mojdehi H., \& Tashakkori, A. (1984). Short communication: Effects of environmental enrichment on the mental and psychomotor development of orphanage children. Journal of Child Psychology and Psychiatry, 25, 643-650.

MARTINEZ, A. M. (1999). Creatividade y genero. Estudio exploratorio de algunos aspectos de la subjetividad de mujeres creadoras mexicanas y cubanas. Artigo não publicado.

MAY, R. (1982). A coragem de criar. Rio de Janeiro: Nova Fronteira.

PIAGET, J. (1993). A linguagem e o pensamento da criança. (6 ${ }^{\mathrm{a}}$ ed.). São Paulo: Martins Fontes.

RIZZINI, I. (1989). A internação de crianças em estabelecimentos de menores: alternativa ou incentivo ao abandono? Espaço-Cadernos de Cultura, 11, 17-38.

ROGERS, C. (1978). Tornar-se pessoa. São Paulo: Martins Fontes.

RUTTER, M. (1980). The long-term effects of early experience. Development Medicine and Child Neurology, 22, 800-815.

SILVA, C. L. (1993). Criatividade: duas formas de pensar. Psicologia: Teoria e Pesquisa, 9, 145-155.

SMOLUCHA, F. (1992). A reconstruction of Vygotsky's theory of creativity. Creativity Research Journal, 5, 49-67.

STEIN, M. I. (1974). Stimulating creativity. Individual procedures. New York: Academic Press.

STERNBERG, J. R. (1988). A three facet-model of creativity. Em R. J. Sterberg (Ed.), The nature of creativity (pp.125-147). New York: Cambridge University Press.

TABACHNICK, B. G., \& Fidell, L. S. (1996). Using multivariate statistics. New York: Harper Collins.

TIZARD, B., \& Hodges J. (1978). The effect of early institutional rearing on the development of eight year old children. Journal of Child Psychology and Psychiatry, 19, 99-118. 
TORRANCE, E. P. (1974). Torrance Tests of Creative Thinking. Norms-Technical Manual. Benseville, IL: Scholastic Testing Service.

TORRANCE, E. P. (1987). Teaching for creativity. Em S. G. Isaksen (Ed.), Frontiers of creativity research: Beyond the basics (pp. 189-215). Buffalo, NY: Bearly Limited.

URBAN, K. K., \& Jellen, H. G. (1996). Test for Creative Thinking - Drawing Production (TCT-DP). Manual. Frankfurt: Swets \& Zeitlinger.

VYGOTSKY, L. S. (1990). Imagination and creativity in childhood. Soviet Psychology, 28, 84-95.
WACHS T. P., \& Gruen G. E. (1982). Early experience and human development. New York: Plenum Press.

WALLON, H. (1995). As origens do caráter na criança. São Paulo: Nova Alexandria.

WEBER, L. N. D., \& Kossobudszki, L. M. M. (1996). Filhos da solidão: institucionalização, abandono e adoção. Curitiba: Governo do Estado do Paraná.

YAROSHEVSKII, M. G. (1987). The psychology of creativity and creativity in psychology. Soviet Psychology, 25, 22-44.

Recebido para publicação em 30 de outubro de 2002 e aceito em 11 de junho de 2003. 
